\title{
Aging and the Motor Unit
}

\section{Jennifer A. Bunn*}

Department of Exercise Science, Campbell University, NC 27506, USA

It has long been known that humans have decreased strength and muscle mass with age, but the mechanisms behind this are still not completely understood. In his review, Degens [1] discusses some potential reasons for this loss in strength with age, concluding that the hypertrophy capability of a muscle fiber does not change as one gets older, but rather that there are fewer muscle fibers. The primary reasoning behind fewer muscle fibers is associated with restructuring and subsequent loss in motor units, as well as a lack of mechanical stimuli from physical activity.

Age-related muscle atrophy occurs with both a decrease in muscle cross-sectional area and a decrease in muscle fiber number. The gradual loss of muscle fibers appears to begin at around 50 years-old, with approximately $50 \%$ of the muscle fibers in the limbs lost by the age of 80 [2], resulting in a loss of $30-50 \%$ of skeletal muscle mass [3,4]. There appears to be a greater loss in lean body mass in the lower body (15\%) than the upper body (10\%) in both men and women [5]. This atrophy is linked to a decline in muscular strength and power [6], and an increase in rate of fatigue as shown in animal models $[7,8]$. The losses in strength and power are associated with a decrease in both the size and number of fast-twitch (type II) muscle fibers. Evidence shows that there is a loss in fast twitch fiber cross-sectional area with age, while slow twitch (type I) fibers appear to maintain their cross-sectional area [4,9]. This loss in fiber size is associated with an age-related decline in growth factors [10], as well as a lack of mechanical stimuli for the fast twitch fiber.

The majority of the literature indicates that muscle fiber loss is due to a loss in motor neurons. There is consistent deinervation and reinervation of the muscle fiber throughout one's lifespan, but in the aged, deinervation appears to outpace reinveration [11,12]. Data indicate that a 60 year-old has approximately $25-50 \%$ fewer motor neurons than a 20 year-old [13] with the greatest losses in distal fast twitch motor neurons $[4,14,15]$. With the loss of the motor neuron, the deinervated fast twitch muscle fibers that were attached to it are either permanently deinervated and undergo apoptosis, or are reinverated with a different motor neuron $[4,16]$, most likely that of a slow twitch neuron, potentially making the fiber take on slow twitch characteristics. This motor unit restructuring is supported by evidence that older men and women have larger motor unit size compared to their younger counterparts [17]. The motor unit number appears to be consistent until the sixth decade of life, but declines by approximately $50 \%$ by the eighth decade [18].

The restructuring of the motor unit does not appear to completly convert the former fast twitch fibers to a slow twitch fiber, but rather the classification of the fibers become convoluted. The confusion in muscle fiber typing is seen because several fibers appear to express both myosin heavy chain-I and II isoforms $[19,20]$. A potential explanation for this is that while the motor neuron loss seen with aging is mostly with fast twitch neurons, the majority of the muscle atrophy associated with lack of physical activity is in slow twitch muscle fibers [20].

The most common solution to muscle atrophy in younger individuals is the stimulus of physical activity. However, even in master athletes who do exercise regularly the loss in muscle fibers is still observed, but at a lower rate [21]. When master weight lifters were compared to untrained controls of the same age, the lifters had greater peak power and peak force production compared to the controls. However, muscle power and isometric strength have been shown to decline at a similar rate for both master lifters and the untrained controls, but because the master lifters had a larger muscle mass than that of the untrained controls, the master lifters then had a twenty year advantage over the untrained controls [21]. Additionally, with the introduction of an exercise stimulus to an elderly individual, the evidence of hypertrophy of slow and fast twitch muscle fibers appears to be equivocal [22,23].

Overall, it is this loss in motor units that appear to drive the loss in muscle fibers [2]. The most commonly utilized reasoning for fewer fibers is based on the principle of reversibility and detraining, or "use or lose it," but this is only a portion of the explanation for the elderly. It appears that despite participation in physical activity, aging individuals still experience a loss in muscle fiber size and number, with the loss in fiber number being driven by a decrease in functional motor neurons. The mechanical stimulus of physical activity does not seem to attenuate this process, but rather provides a better physiological foundation so that trained older individuals have more lean mass than that of their untrained counterparts. The relationship between aging and disuse is complex, but perhaps more answers can be found in the future with a larger focus in studying master athletes.

\section{References}

1. Degens H (2012) Determinants of skeletal muscle hypertrophy and the attenuated hypertrophic response to old age. J Sports Med Doping Stud.

2. Faulkner JA, Larkin LM, Claflin DR, Brooks SV (2007) Age-related changes in the structure and function of skeletal muscles. Clin Exp Pharmacol Physiol 34 1091-1096.

3. Akima $\mathrm{H}$, Kano $\mathrm{Y}$, Enomoto $\mathrm{Y}$, Ishizu M, Okada M, et al. (2001) Muscle function in 164 men and women age 20--84 yr. Med Sci Sports Exerc 33: 220-226.

4. Lexell J, Taylor CC, Sjöström M (1988) What is the cause of the ageing atrophy? Total number, size, and proportion of different fiber types studied in whole vastus lateralis muscle from 15- to 83 -year-old men. J Neurol Sci 84 : 275-294.

5. Janssen I, Heymsfield SB, Wang ZM, Ross R (2000) Skeletal muscle mass and distribution in 468 men and women aged 18-88 yr. J Appl Physiol 89: 81-88.

6. Skelton DA, Grieg CA, Davies JM, Young A (1994) Strength, power, and related functional ability of healthy people aged 65-89 years. Age Ageing 23: 371-377.

7. Brooks SV, Faulkner JA (1991) Forces and power of slow and fast skeleta muscles in mice during repeated contractions. J Physiol 436: 701-710.

8. Faulkner JA, Brooks SV (1995) Muscle fatigue in old animals. Unique aspects of fatigue in elderly humans. Adv Exp Med Biol 384: 471-480.

9. Lexell J (1995) Human aging, muscle mass, and fiber type composition. J Gerentol A Biol Sci Med Sci 50: 11-16.

10. Barton-Davis ER, Shoturm DI, Sweeney HL (1999) Contribution of satellite cells to IGF-1 induced hypertrophy of skeletal muscle. Acta Physiol Scand 167: 301 305

*Corresponding author: Jennifer A. Bunn, Department of Exercise Science, Campbell University, PO Box 414, Buies Creek, NC 27506, USA, Tel: 910-8931361; E-mail: bunnj@campbell.edu

Received June 11, 2012; Accepted June 13, 2012; Published June 16, 2012

Citation: Bunn JA (2012) Aging and the Motor Unit. J Sport Medic Doping Studie S1:e001. doi:10.4172/2161-0673.S1-e001

Copyright: (c) 2012 Bunn JA . This is an open-access article distributed under the terms of the Creative Commons Attribution License, which permits unrestricted use, distribution, and reproduction in any medium, provided the original author and source are credited. 
11. Luff AR (1998) Age-associated changes in the innervations of muscle fibers and changes in the mechanical properties of motor units. Ann N Y Acad Sci 854: 92-101.

12. Narici MV, Maffulli N (2010) Sarcopenia: characteristics, mechanisms, and functional significance. Br Med Bull 95: 139-159.

13. Kawamura Y, O’Brien P, Okazaki H, Dyck PJ (1977) Lumbar motoneurons of man II: Numbers and diameter distributions of large- and intermediate-diameter cytons in motoneuron columns of spinal cord of man. J Neuropathol Exp Neurol 36: $861-870$

14. Doherty TJ, Brown WF (1993) The estimated numbers and relative sizes of thenar motor units as selected by multiple point stimulation in young and older adults. Muscle Nerve 16: 355-366

15. Galea V (1996) Changes in motor unit estimates with aging. J Clin Neurophysiol 13: $253-260$.

16. Porter MM, Vandervort AA, Lexell J (1995) Ageing of human muscle: structure, junction, and adaptability. Scand J Med Sci Sports 5: 129-142.

17. Stalberg E, Fawcett PR (1982) Macro EMG in healthy subjects of different ages. J Neurol Neurosurg Psychiatry 45: 870-878.
18. Lexell J, Hendriksson-Larson K, Winblad B, Sjöström M (1983) Distribution of different fiber types in human skeletal muscle: effects of aging studied in whole muscle cross sections. Muscle Nerve 6: 588-595.

19. Klitgaard H, Bergman O, Betto R, Salviati G, Schiaffino S, et al. (1990) Coexistence of myosin heavy chain I and Ila isoforms in human skeletal muscle fibers with endurance training. Pfluger Arch 416: 470-472.

20. D'Antona G, Pellegrino MA, Adami R, Rossi R, Carlizzi CN, et al. (2003) The effect of ageing and immobilization on structure and function of human skeletal muscle fibers. J Physiol 552: 499-511.

21. Pearson SJ, Young A, Macaluso A, Devito G, Nimmo MA, et al. (2002) Muscle function in elite master weight lifters. Med Sci Sports Exerc 34: 1199-1206.

22. Trappe S, Goddard M, Gallagher P, Carroll C, Rowden G, et al. (2001) Resistance training improves single muscle fiber contractile function in older women. Am J Physiol Cell Physiol 281: C398-C406.

23. Widrick JJ, Stelzer JE, Shoepe TC, Garner DP (2002) Functional properties of human muscle fibers and short-term resistance exercise training. Am J Physiol Regul Integr Comp Physiol 283: R408-R416.
This article was originally published in a special issue, Muscle Hypertrophy handled by Editor(s). Dr. Jennifer A. Bunn, Campbell University, USA 